\title{
A IMPORTÂNCIA DA UTILIZAÇÃO DO LABORATÓRIO DE ENSINO DE MATEMÁTICA COMO UMA FERRAMENTA ATIVA NA ALAVANCAGEM DO PROCESSO DE APRENDIZADO DA DISCIPLINA DE MATEMÁTICA
}

\author{
THE IMPORTANCE OF THE USE THE MATHEMATICS TEACHING \\ LABORATORY AS AN ACTIVE TOOL IN LEVERAGING THE LEARNING PROCESS \\ OF THE MATHEMATICS DISCIPLINE
}

\author{
Fabiano Della Libera da Silva ${ }^{1}$
}

\begin{abstract}
RESUMO: Este artigo apresenta o surgimento e a importância do Laboratório de Ensino de Matemática (LEMAT) como uma ferramenta altamente eficaz para a quebra do paradigma de que o processo de ensino-aprendizagem da disciplina de Matemática é algo muito difícil e distante do alcance da maioria dos estudantes. Busca-se também o estudo sobre a importância e das possibilidades que possam existir em relação à sua utilização para o ensino e a aprendizagem que o seu uso possa proporcionar em diferentes etapas do aprendizado, em diferentes níveis e modalidades de ensino, além de poder oferecer um importante aporte para formação inicial de professores. Desta forma, o trabalho poderá auxiliar na sugestão de materiais manipuláveis que possam ser utilizados juntamente com o LEMAT para que juntos, possam alavancar o aprendizado significativo e sugerir mudanças nos encaminhamentos metodológicos da atuação do professor de Matemática em sala de aula. Para tanto, foi construído um estudo bibliográfico sobre o LEMAT de acordo com a visão de alguns teóricos sobre o assunto no intuito de levantar trabalhos que possam contribuir.
\end{abstract}

Palavras-chave: Laboratório; Matemática; Alavancar; Aprendizagem.

ABSTRACT: This article presents the emergence and importance of the Mathematics Teaching Laboratory (LEMAT) as a highly effective tool for breaking the paradigm that the teaching-learning process of Mathematics is very difficult and far from the reach of most students. It also seeks to study the importance and possibilities that may exist in relation to its use for teaching and learning that its use can provide in different stages of learning, in different levels and modalities of teaching, besides being able to offer an important contribution to initial teacher training. In this way, the work can help in the suggestion of manipulable materials that can be used together with the LEMAT so that together they can leverage meaningful learning and suggest changes in the methodological directions of the teacher's performance in the classroom. To do so, a bibliographic study on LEMAT was constructed according to the view of some theoreticians on the subject in order to collect works that could contribute.

Keywords: Laboratory; Mathematics; Leverage; Learning.

\section{INTRODUÇÃO}

Já é de conhecimento de todos que a disciplina de Matemática é preterida por uma grande quantidade de estudantes que muitas vezes não veem ligação entre o que é

\footnotetext{
${ }^{\text {I }}$ Mestre em Engenharia pela UFRGS; MBA em Gerenciamento de Projetos pela FGV; Engenheiro de Produção Civil pela UCL e graduando em Licenciatura em Matemática pela UNINTER. fabianodella@gmail.com.
} 
ensinado em sala de aula com o seu dia-a-dia, ou seja, na maior parte do tempo a disciplina se mostra desconexa com a realidade dos estudantes. Uma grande quantidade pesquisas trouxeram alguns questionamentos a respeito das dificuldades no processo de ensino-aprendizagem, como por exemplo: existem deficiências no processo de ensinoaprendizagem nos ensinos fundamental e médio? Estas deficiências têm relação com a formação do professor de Matemática? O que pode ser feito para que o ensino da disciplina de Matemática seja mais atraente para os estudantes ou possa trazer uma forma de ensino que aproxima os estudantes das suas realidades?

Segundo Cunha (2017), a matemática pode ser vista nos mais diferenciados segmentos da vida cotidiana e pode ser vista em todas as tarefas executadas do nosso dia a dia, seja na compra de um de um litro de leite na padaria como na aplicação de um grande investimento financeiro ou até nas análises mais complexas no mundo corporativo. Desta forma, ao acordar, nosso relógio do celular ou um despertador expressa as horas utilizando o princípio da contagem do tempo, quando fazemos uma refeição, por exemplo, utilizamos o conceito da proporção, e assim por diante. Por outro lado, a matemática é aceita com grande insatisfação pela comunidade escolar, pois exige, muitas vezes, dos estudantes um grau de memorização e uma ampla linha de raciocínio, esta dificuldade encontrada que os fazem distanciar-se de sua prática no cotidiano.

Segundo Lorenzato (2006), os materiais didáticos podem ser constituídos de qualquer instrumento útil que possa ser utilizado no processo de ensino-aprendizagem, como por exemplo, calculadoras, jogos, filmes, imagens gráficas, etc. Os materiais manipuláveis têm uma função primordial de contribuir no desenvolvimento dos conceitos matemáticos por serem de fácil construção pelos mesmos com a orientação do professor.

Existem vários tipos de $\mathrm{MD}$ manipulável. Alguns não possibilitam modificação em suas formas; é o caso dos sólidos geométricos construídos em madeira ou cartolina, por exemplo, que por serem estáticos, permitem só a observação. Outros já permitem só a observação. Outros já permitem uma maior participação do aluno: é o caso do ábaco, do material montessoriano (cuisenaire ou dourado), dos jogos de tabuleiro. (LORENZATO, 2006, p.18) 
Corroborando com a mesma ideia, Oliveira e Sousa (2010), sustentam que a união entre os materiais manipuláveis e os jogos são exemplos de ótimos materiais didáticos uma série de conceitos e conteúdos da disciplina de Matemática de forma multidisciplinar e também fazendo o uso de temas transversais.

O Laboratório de Ensino de Matemática (LEMAT), na visão de Lorenzato (2012, p7) se trata de uma sala-ambiente voltada para a estruturação, a organização e o planejamento do pensamento matemático de forma que este ambiente venha propiciar que tanto o professor quanto o aluno venham experimentar, conjecturar, questionar, procurar, analisar e fazer conclusões e aprender a aprender. De acordo com Abreu (1997, p. 5o), o LEMAT é o local onde o aluno irá criar novas soluções para os problemas apresentados em sala, de forma que o aluno possa trabalhar com atividades lúdicas e refletir sobre ideias matemáticas.

\section{FUNDAMENTAÇÃO TEÓRICA}

No Brasil, durando o período republicano, foi um período que se destacam na história da educação brasileira, quando se manifestam claramente os princípios do positivismo. Nesta visão, o ensino se caracteriza por ser enciclopédico valorizando a ciência e uma educação utilitarista. Segundo Souza Santos (1988, p. 4), dentro do positivismo de Augusto Comte (1789 - 1857) a Matemática ocupa um lugar central caracterizando-se como um conjunto de ideias a partir das quais se pode ascender a um conhecimento mais profundo e rigoroso da natureza.

Segundo Tahan (I96I, p. 6I), em uma das principais obras sobre o LEMAT no Brasil, se refere ao LEMAT como um local onde o ensino da Matemática é apresentado "ao vivo" com o auxílio de materiais adequados à maior eficiência da aprendizagem. $\mathrm{O}$ autor ainda reforça que o LEMAT é um espaço físico onde caracteriza-se como uma sala ambiente na qual se encontram as peças consideradas úteis, interessantes ou mesmo indispensáveis ao ensino da Matemática.

Lorenzato (2006) sugere que os materiais manipuláveis são um bom caminho para a construção do chamado "saber matemático" de modo que Passos (2006) reforça que estes materiais servem como mediadores na relação professor-aluno-conhecimento e destaca que existe uma necessidade de se haver uma maior discussão de caráter 
epistemológico sobre a utilização destes recursos na formação dos professores. Lorenzato (2006) ainda reforça que diversos profissionais da área da educação destacam de forma unânime a importância do apoio visual ou visual tátil como facilitador da aprendizagem. Em relação ao Laboratório de Ensino de Geometria da Universidade Federal Fluminense (UFF), segundo Kaleff (2006), o uso dos materiais manipuláveis e atividades didáticas desenvolvidas neste tipo de ambiente têm como objetivo levar o aluno a entrar em contato visual com as formas geométricas e analisar suas características.

Uma grande quantidade de pesquisas acadêmicas apresenta uma visão bem enfática da necessidade do uso do LEMAT no espaço da universidade, no momento da formação do professor de Matemática, porém, nota-se que existe um certo déficit no currículo destes profissionais, principalmente no que se trata da implantação ou mesmo da utilização destes espaços nas suas cargas horárias durante a sua formação. De acordo com Lorenzato (2006, p.12) reforça esta mesma ideia de que é facilmente constatável na prática escolar que muitos professores não conhecem um LEMAT, outros ainda desprezam o uso de um Laboratório sem mesmo terem experimentado, e alguns o empregam de forma inadequada.

Segundo Oliveira (1983), de acordo com uma pesquisa diagnóstica realizada em seu trabalho onde o mesmo verificou muitos problemas, a exemplo da falta de hábito de reflexão pelos alunos, que lhes faltam raciocínio para a análise e a busca do significado de cada definição ou de cada conceito de modo que possa interpretar os enunciados $O$ autor ainda diz que o fato de existir uma falta de materiais didáticos, livros e metodologias somados a outros vários problemas levantados por ele. $\mathrm{O}$ autor ainda reforça que as reflexões do seu trabalho levam à evidência de que existe uma necessidade de aperfeiçoamento no currículo do curso de licenciatura de Matemática da UFPR e que, uma vez evidenciado isto, são necessários muitos estudos e experiências que permitam a reformulação de programas, objetivos e métodos para o ensino da disciplina de Matemática.

Com propósito semelhante, conforme visto em Libãneo (2008, p.65), devemos ter a aprendizagem do aluno como referência para as atividades de ensino. Devemos ter 
o "como se ensina" atrelado ao "como os estudantes aprendem". Por exemplo, Kline (1976) quando analisa propostas nos conteúdos utilizados para o ensino da Matemática nos Estados Unidos se diz acreditar na possibilidade de uma melhoria no processo ensino-aprendizagem da disciplina de Matemática se houver uma formação sólida do corpo docente. Segundo Piaget (1978), as dificuldades de ensino-aprendizagem da Matemática estão atreladas diretamente à incapacidade do aluno se adaptar ao método de ensino que o professor utiliza. Portanto, isso nos leva a entender que, neste caso, o professor necessita mudar o seu método ou criar novas situações ou se valer de outras metodologias de forma que o ensino se torne convincente e eficaz.

De acordo com Piaget (1978), "Uma experiência que não seja realizada pela própria pessoa, com plena liberdade de iniciativa, deixa de ser por definição, uma experiência, transforma-se em simples adestramento". O próprio conceito de experiência trazido aqui por Piaget, o LEMAT é um ambiente propício para a prática pedagógica na forma de experiência. Neste contexto, o LEMAT é entendido como o espaço onde se criam situações e condições para as questões aqui detectadas. Lorenzato (2006) afirma que vários educadores no decorrer da história destacaram a importância do apoio visual ou visual tátil como facilitador da aprendizagem. Já em Tahan (1962, p.6 2) vemos que o professor de Matemática que tiver em sua disposição um bom Laboratório poderá motivar os seus estudantes com maior facilidade, por meio de experiências e orientá-los mais tarde, com maior segurança, pelo caminho das pesquisas abstratas.

De acordo com Turrioni e Perez (2009), o LEMAT se caracteriza por ser um local diferenciado da sala de aula, ou até uma extensão da mesma, de forma que os futuros professores e pedagogos possam desenvolver trabalhos de forma informal e possam trabalhar, movimentar, discutir e escolher materiais e descobrir novas metodologias e, enfim, poder fazer um bom trabalho com um maior grau de autonomia. Deste modo, o LEMAT se representa como um lugar para subsidiar o trabalho com a inserção do lúdico, com representações visuais e táteis, com a problematização de conceitos e teoremas matemáticos e, portanto, com o interesse tanto do futuro professor como das crianças pela matemática. 
Segundo Tahan (1961), concebe o LEMAT não só como um método de ensino e aprendizagem em Matemática como também destaca uma ideia de que o LEMAT como uma sala separada com recursos disponíveis como um espaço disponível para experiências mais "concretas". O autor ainda enumera certas condições necessárias para que possamos chegar próximo a um bom LEMAT, como por exemplo, a) instalações móveis: o LEMAT deverá ser instalado em uma sala ampla, bem arejada, como capacidade entre 35 e 40 estudantes no máximo; b) Possuir materiais de apoio como caixa de giz branco, caixa de giz de cores, apagadores, tesouras, blocos de papel (sem pauta e quadriculado), pedaços de arame, pedaços de cartolina, pedaços de papelão, rolos de barbante, etc.; c) Possuir material bibliográfico como livros didáticos, dicionários, formulários, tábuas de logaritmos, tabelas numéricas, obras de consulta, etc.; d) Possuir instrumentos para desenho e aparelhagem para medidas; e) Possuir modelos de figuras geométricas planas em arame, cartolina e em matéria plástica com indicação dos eixos de simetria além de modelos em flanelógrafo; f) Possuir modelos sólidos geométricos; g) Possuir coletânea de desenhos, fotografias e esquemas como pontes, edifícios, catedrais, monumentos, aviões, etc. Mapas coloridos para estudos sobre escalas, cálculo de distâncias, fuso horários, etc.; h) Possuir materiais permanentes para jogos de aprendizagem; i) Possuir objetos para recreação matemática: torre de Hanói, quadrados mágicos, quadros para adivinhações numéricas, tabuleiro de xadrez com suas peças, jogo de damas completo; j) Possuir jogos para recreações como dominó e baralho comum; k) Possuir retratos de matemáticos famosos, incluindo grandes matemáticos brasileiros, retratando a evolução e o desenvolvimento da matemática.

Todas as práticas pedagógicas planejadas nas Diretrizes Curriculares da Educação Básica do Estado do Paraná (DCE), tem como base as discussões sobre as concepções teórico-metodológicas frente ao saber educativo. De acordo com a DCE (2008, p.28):

É preciso, porém, que o professor tenha cuidado para não empobrecer a construção do conhecimento em nome de uma prática de contextualização. Reduzir a abordagem pedagógica aos limites da vivência do aluno compromete o desenvolvimento de sua capacidade crítica de compreensão da abrangência dos fatos e fenômenos. Daí a argumentação de que o contexto 


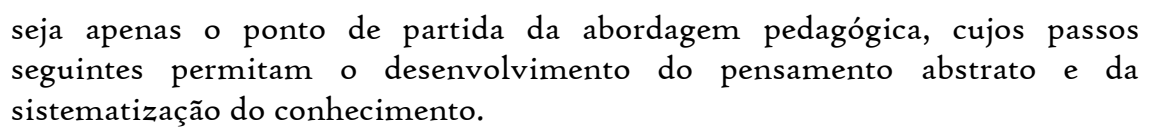

As justificativas para a implementação de um LEMAT são muitas, por exemplo, a sua implementação numa instituição de Ensino Superior conforme visto em Rêgo e Rêgo (2006, p.4I), poderá incentivar em muito a melhoria da formação inicial e continuada de professores, promover uma melhor integração das ações de ensino, pesquisa e extensão, como também favorece o estreitamento da relação entre a instituição e a comunidade, além de estimular a prática da pesquisa em sala de aula

\section{METODOLOGIA}

A metodologia de uma pesquisa, como o próprio nome sugere, tem o intuito de abordar os caminhos trilhados [os métodos] utilizados para que sejam atingidos os objetivos da pesquisa. Quanto aos procedimentos, foi optado pela pesquisa Bibliográfica e entende-se por pesquisa bibliográfica a revisão da artigos científicos, livros, periódicos, etc.

Em relação à abordagem da pesquisa foi optado pela abordagem qualitativa pois, nesta abordagem, existe um levantamento e coleta de dados e informações sobre as motivações de um grupo que são mais subjetivos na busca de compreender e de interpretar determinados comportamentos, opinião, expectativa, sentimentos, percepções, entre outros aspectos imateriais.

Quanto aos objetivos da pesquisa, optou-se pela pesquisa explicativa de forma que esta venha identificar os fatores que determinam os fenômenos relacionados aos problemas aqui levantados.

A Ontologia é a parte da metafísica que trata da natureza, realidade e existência dos entes e, podemos dizer que ontologicamente, a realidade constitui-se por diferentes modos de compreensão: a realidade objetiva, porém, é tangível, externa ao sujeito e com possibilidade de ser completamente conhecida. Já a realidade percebida, que não poderia ser conhecida totalmente, mas tão somente percebida em determinados ângulos. A realidade construída, resultado de uma construção na mente das pessoas, oferecendo dúvidas à sua existência com possibilidade de ser completamente conhecida e, sendo 
assim, a realidade seria uma construção complexa de múltiplas realidades. A realidade criada, parte do pressuposto de que a realidade não existe como tal, que se trataria de uma probabilidade matemática, do mundo subatômico, das partículas. A realidade virtual, como aquilo que tem uma existência aparente e não real, atribuída ao universo das tecnologias da informação e comunicação (BOLÍVAR, 2008; LINCOLN \& GUBA, 1985).

Segundo Flick (2004, p.43), a pesquisa qualitativa caracteriza-se como um processo de interpretação e compreensão, não se contentando com a simples explicação das realidades. Desta forma, segundo o autor "[a] realidade estudada pela pesquisa qualitativa não é uma realidade determinada, mas é construída por diferentes 'atores'”.

$\mathrm{Na}$ abordagem qualitativa, não existe um intuito na obtenção de números como resultados conforme a abordagem quantitativa, mas o intuito então é de entender qual o caminho para a tomada de decisão correta sobre o problema do seu tema.

De acordo com Minayo (1993),

$$
\begin{aligned}
& \text { a pesquisa qualitativa responde a questões muito particulares. Ela se preocupa, } \\
& \text { nas ciências sociais, com um nível de realidade que não pode ser quantificado, } \\
& \text { ou seja, ela trabalha com o universo de significados, motivos, aspirações, } \\
& \text { crenças, valores e atitudes, o que corresponde a um espaço mais profundo das } \\
& \text { relações dos processos e dos fenômenos que não podem ser reduzidos à } \\
& \text { operacionalização de variáveis. (p. 2I) }
\end{aligned}
$$

No mesmo sentido, Fiorentini e Lorenzato (2006, p.IIo), destacam que a abordagem qualitativa "busca investigar e interpretar o caso como um todo orgânico, uma unidade em ação com dinâmica própria, mas que guarda forte relação com seu entorno e contexto sociocultural”. É uma metodologia onde o pesquisador "procura explicitar as causas dos problemas ou fenômenos, isto é, busca o porquê das coisas. É comum a pesquisa explicativa apoiar-se numa investigação exploratória ou descritiva”. Esses autores ainda reforçam que as pesquisas descritivas e explicativas podem envolver o "Levantamento bibliográfico, realização de entrevistas, aplicação de questionários ou testes, ou até mesmo estudo de casos”.

Em relação às fontes, se tratam de onde serão buscadas as informações que servirão como base que sustentarão de forma objetiva os argumentos que serão expostos neste trabalho. As informações serão buscadas de trabalhos científicos como por 
exemplos artigos científicos, dissertações e teses podendo ainda incluir ainda outras publicações em periódicos ou revistas acadêmicas. Os resultados desta pesquisa foram expostos de forma qualitativa.

Em relação aos procedimentos e técnicas do trabalho, que é considerado o momento propício onde são selecionadas as técnicas que foram utilizadas para fazer a coleta dos dados. Entretanto, nesta etapa, segundo a literatura sobre o assunto, é primordial que sejam relacionados os procedimentos que serão aplicados durante uma determinada pesquisa com o objetivo de alcançar os resultados esperados. As técnicas utilizadas devem se relacionar com o propósito e com a abordagem da pesquisa. Para este fim, existem diversos métodos para a coleta de dados, como por exemplo, análise documental, revisão bibliográfica, pesquisa de campo, entre outros. Considerando que a técnica ideal que está mais próxima ao objetivo proposto por este trabalho, foi optada pela revisão bibliográfica.

\section{${ }_{4}$ CONSIDERAÇÕES FINAIS}

Foi constatado por meio deste trabalho que a disciplina de Matemática é aplicada, em sua maioria das vezes, de uma forma descontextualizada, fazendo que haja uma distância entre a realidade vivenciada pelo aluno e o que é ensinado em sala de aula. Este problema faz com que os estudantes não se engajem de forma objetiva e passam a ter medo da disciplina de forma que o seu processo de aprendizagem esteja comprometido. Desta forma, não só existe desinteresse do aluno como também existe uma falência mais ampla de todo o processo ensino-aprendizagem do aluno. Muitas dificuldades são enfrentadas no dia-a-dia do ensino em todas as disciplinas, porém, trazendo somente aqui para nosso contexto do ensino da Matemática, podemos citar alguns problemas como o espaço físico inadequado que permeia deste a ambientes físicos inadequados até a quantidade muito grande de estudantes. Outro problema enfrentado pelos professores é a falta de ferramentas para que o professor atue com mais eficiência. Podemos concluir também que o professor é a peça fundamental e também um agente importantíssimo em todo este contexto de mudança na forma de trabalhar sendo ainda o principal agente responsável por adotar em suas aulas as novas formas de trabalho e inovações contextualizadas que a matemática apresenta nos dias 
atuais, buscando do aluno uma participação mais ativa através de demonstrações de fenômenos do dia-a-dia e também mostrando exemplos e fazendo uma junção objetiva entre os conteúdos da disciplina e o dia-a-dia dos estudantes.

Sabemos que a Matemática é uma ferramenta que serve não só para a vida acadêmica, através de demonstrações de teoremas e aplicações de conceitos mais bem elaborados e complexos, como também para a nossa vida cotidiana, através da contagem das horas no relógio e da soma das mercadorias que compramos no supermercado, de modo, então, que esta disciplina possa contribuir desde as Séries Iniciais da formação do aluno até a formação da identidade docente. Foi possível verificar através de todo o material pesquisado que, em diversos locais os quais o LEMAT foi implantado, de modo que foi possível ser sentido por todos os envolvidos, a mudança de ambiente escolar gerando um novo ambiente de estudo e propiciando um desenvolvimento de pesquisas na área de educação matemática.

Através deste trabalho foi possível verificarmos que a utilização do material concreto tem um papel muito importante na relação ensino-aprendizagem e, conforme foi visto em Turrioni e Perez (2006, p.6I), estes materiais facilitam a observação e a análise, desenvolve o raciocinio lógico, crítico e científico, e são fundamentais para o ensino experimental, além de serem excelentes para auxiliar o aluno na construção de seus conhecimentos. Foi observado que quando existe a oportunidade da construção e da eleboração de práticas diferenciadas, podemos contribuir de forma significativa para a alavancagem do aprendizado significativo, fazendo com que os estudantes possam superar as suas dificuldades e, desta forma, podemos fazer com que haja uma maior aprendizagem além de termos uma disciplina muito mais voltada para o dia-a-dia do aluno e este aluno possa identificar a matemática que ele aprendeu em sala no seu contexto de vida.

Também foi possível verificar através desta pesquisa que o LEMAT vem trazendo contribuições significativas para a maioria dos estudantes do curso de licenciatura do Instituto Federal de Pernanbuco (IFPE - Campo Pesqueira), isto porque neste ambiente possui um ambiente confortável, com computadores ligados à internet, 
com materiais diversos, com conteúdos de Matemática e alguns livros didáticos. Em se tratando da dificuldade da implantação de um LEMAT, Lorenzato (2006, p. 34) afirma:

\begin{abstract}
"Se for verdadeiro que ninguém "ama o que não conhece", então fica explicado porque tantos estudantes não gostam de matemática, pois se a eles não foi dado conhecer a matemática, como podem vir a admirá-la? No entanto com o auxílio de $\mathrm{MD}_{2}$, o professor pode, se empregá-lo corretamente, conseguir uma aprendizagem com compreensão, que tenha significado para o aluno, diminuindo, assim, o risco de serem criadas ou reforçadas falsas crenças referentes à matemática, como a de ser ela uma disciplina "só para poucos privilegiados", "pronta", "muito difícil”, e outras semelhantes. Outra consequência provável se refere ao ambiente predominante durante as aulas de matemática, onde o temor, a ansiedade ou a indiferença serão substituídos pela satisfação, pela alegria ou pelo prazer. Mas, talvez, o mais importante efeito será o aumento da autoconfiança e a melhoria da auto-imagem do aluno".
\end{abstract}

Podemos verificar em Lorenzato (2006), além das vantagens apontadas pelos estudantes e professores, o uso do LEMAT facilita o acesso a alguns materiais em situações de aprendizagens não previstas no planejamento do professor, más que acabam ocorrendo na prática, conforme os questionamentos dos estudantes em aula.

\title{
REFERÊNCIAS
}

ABREU, Maristela Dalla Porta de. Laboratório de Matemática: um espaço para a formação continuada do professor - Dissertação de Mestrado. Santa Maria: UFSM, 1997.

BOLÍVAR, C. R. (2008). El enfoque multimétodo en la investigación social y educativa: Una mirada desde el paradigma de la complexidad. Revista de Filosofía y Socio Política de la Educación, 8(4), 13-28.

CUNHA, Cézar Pessoa. A Importância da Matemática no Cotidiano. Revista Científica Multidisciplinar Núcleo do Conhecimento. Edição 04. Ano 02, Vol. or. pp 64I-65o, Julho de 2017. ISSN:2448-0959

DCE. Paraná. Secretaria de Estado de Educação. Diretrizes Curriculares da Educação Básica: Língua Portuguesa. Curitiba: SEED, 2008

FLICK, U. Uma introdução à pesquisa qualitativa. Porto Alegre: Artmed. 2004.

KALEFF, A. M. M. R. Do fazer concreto ao desenho em geometria: ações e atividades desenvolvidas no laboratório de ensino de geometria da Universidade Federal Fluminense. In: LORENZATO, S. (ED) O Laboratório de Ensino de Matemática na formação de professores. São Paulo: Autores Associados, p. I13-134, 2006.

${ }^{2} \mathrm{MD}$ é a abreviatura de Material Didático utilizada pelo autor. 
KLINE, Morris O Fracasso da Matemática Moderna. São Paulo SP, Ibrasa, 1976. P. 40.

LORENZATO, Sérgio (org.). O Laboratório de Ensino de Matemática na formação de professores. I ${ }^{\mathrm{a}}$. Ed. Campinas, SP: Autores Associados, p. 3-37, 2006 (Coleção Formação de Professores).

LORENZATO, Sergio (org.). O laboratório de ensino de matemática na formação de professores. Campinas, SP: Autores Associados, 2012. (Coleção formação de professores).

LINCOLN Y. S., \& GRUBA, E. G. (1985). Naturalistic inquiry. Beverly Hills, CA: Sage. MINAYO, M.C.S. Pesquisa social: Teoria, método e criatividade. Rio de Janeiro: Vozes, 1993.

OLIVEIRA, A. M. N. Laboratório de Ensino e Aprendizagem em Matemática. Dissertação (Mestrado em Educação) - Departamento de Educação, Universidade Federal do Paraná, PR, 1983.

OLIVEIRA, José D. S.; SOUSA Giselle C. O Uso de Materiais Manipuláveis e Jogos no Ensino de Matemática. X Encontro Nacional de Educação Matemática. Universidade Federal do Rio Grande do Norte, julho de 2010

PASSOS, Carmen Lúcia Brancaglion. Materiais manipuláveis como recursos didáticos na formação de professores de matemática. In: LORENZATO, Sérgio (Org.) O Laboratório de Ensino de Matemática na formação de professores. Campinas, SP: Autores Associados, p. 77-92, 2006.

PIAGET, Jean. Para onde vai a educação? 6. Ed. Rio de Janeiro, J. Olympio, 1978. 8 o p.

PONTE, J. P., BROCARDO, J., OLIVEIRA H. Investigações matemáticas na sala de aula. Vol. 7. Autêntica Editora, 2oor.

PONTE, J. P.; BROCARDO, J.; OLIVEIRA, H. Investigações Matemáticas na sala de aula. Belo Horizonte: Autêntica, 2009.

RÊGO, R.M.; RÊGO, R.G. Desenvolvimento e uso de materiais didáticos no ensino de matemática. In: LORENZATO, Sérgio. Laboratório de Ensino de Matemática na formação de professores. Campinas: Autores Associados, 2006. p.39-56

TAHAN, M. Didática da Matemática. 3.ed. São Paulo: Saraiva, I96r. 2 v.

TAHAN, M. Matemática Divertida e Delirante. São Paulo: Saraiva, 1962.

TURRIONI, Ana Maria Silveira; PÉREZ, Geraldo. Implementando um laboratório de educação matemática para apoio na formação de professores. In: LORENZATO, Sérgio (Org.) O Laboratório de Ensino de Matemática na formação de professores. Campinas, SP: Autores Associados, p. $57-76,2006$. 
TURRIONI, Ana Maria Silveira. PEREZ, Geraldo. Implementando um laboratório de educação matemática para apoio na formação de professores. In: LORENZATO, Sergio. O Laboratório de Ensino de Matemática na Formação de Professores. zed. Campinas, SP: Autores Associados, 2009.

VARIZO, Z.C.M. O Laboratório de Educação Matemática do IME/UFG: Do sonho a realidade. In: ENEM, I0, 2007, Belo Horizonte. Anais... Belo Horizonte, 2007. p.I-I2. 